\title{
Una aproximación a la segunda generación de inmigrantes árabes en Occidente desde la LIJ: el caso de Does my head look big in this? y su traducción al árabe
}

\section{Beatriz Soto Aranda}

El estudio se enmarca dentro de los estudios de traducción centrados en la representación del fenómeno migratorio en la literatura infantil y juvenil (LIJ) y tiene por objeto analizar Does my head look big in this?, novela en la que la escritora australiana de origen palestino-egipcio Randa Abdel-Fattah explora la identidad de la segunda generación de inmigrantes árabes en Australia. En primer lugar, se describe la configuración de la identidad de los hijos de familias inmigradas y su relación con la sociedad australiana y las de origen. En segundo lugar, se analiza el uso de la censura en la traducción al árabe y el modo en que esta técnica de traducción ha condicionado el trasvase de dicha configuración.

Palabras clave: inmigración, segunda generación, árabe, identidad, LIJ, traducción.

An approach from CYA literature to the second generation of Arab immigrants in the West: Does my head look big in this? and its translation to Arabic as a case of study. The study is framed within Translation Studies focused on the representation of the migratory phenomenon in children's and young adults' (CYA) literature, and aims to analyse the construction of identity of the second generation of Arab migrants in Australia, and their relationship with Australian society and those of origin, in Does my head look big in this? first novel of the Australian writer of Palestinian-Egyptian background Randa Abdel-Fattah. Adding to that, the use of censorship in translation into Arabic and how this translation technique has conditioned the transfer of said configuration is analysed.

Keywords: immigration, second generation, Arabic, identity, CYA Literature, translation. 


\section{Objetivo y metodología del estudio}

El estudio tiene por objeto analizar la configuración la identidad de la segunda generación de inmigrantes árabes en Australia en la novela juvenil Does my head look big in this? (Abdel-Fattah 2005). Asimismo, estudia el uso de la censura en su traducción al árabe y el modo en que esta técnica de traducción ha condicionado el trasvase de dicha configuración. La metodología empleada es la propia de los estudios descriptivos de traducción (EDT). Estos asumen que las traducciones pertenecen a la cultura que las genera (Hermans 1999), pudiendo ser interpretadas como discursos sobre la cultura que produce los textos originales, sujetos "a los mecanismos y estrategias de poder que colaboran en la creación de la propia imagen de la cultura de destino contrastándola con las imágenes estereotipadas del Otro" (Carbonell 1998: 194). De este modo, La traducción pasa de interpretarse exclusivamente como una transacción lingüística o textual, a concebirse como un proceso de comunicación intercultural.

A su vez, los EDT estudian las normas que condicionan la publicación de una obra, especialmente las preliminares (aquellas que deciden qué obras se traducen y publican y en qué condiciones) y las operacionales (centradas en las técnicas y estrategias de traducción empleadas) (Toury 1995). En este sentido, la censura es un fenómeno ampliamente estudiado (Cronin 2000 y Tymoczko 2006) con importantes repercusiones ideológicas y culturales, pues condiciona la forma en que texto es representado en otro marco cultural y lingüístico (Hermans 2007). Asimismo, se trata de una técnica habitual en la traducción de LIJ, pues este tipo de obras son susceptibles de mayores transformaciones textuales al quedar fuera del canon literario (Shavit 2006). De este modo, prima la domesticación como estrategia de traducción, esto es, la eliminación o neutralización de los elementos del texto origen (TO) que pudieran resultar extraños en el contexto cultural en el que se publica la traducción, y la consiguiente dependencia de las normas socio-culturales imperantes en la cultura meta (Venuti 1995), y no tanto su grado de correspondencia con el TO (Pascua Febles 1998).

\section{Does my head look big in this? en el marco de la LIJ occidental de temática arabo-islámica}

Junto a su faceta de entretenimiento, la LIJ desempeña un importante papel en la configuración del ideario colectivo, cartografiando los retos 
sociales y culturales a los que se enfrentan las sociedades actuales y los cambios en los cánones establecidos (Gómez Pato 2011). En este sentido, en las últimas décadas, la LIJ no solo se ha aproximado al fenómeno migratorio arabo-islámico y su repercusión en las sociedades de acogida occidentales (Soto Aranda 2019a) sino que ha dado voz a la segunda generación a través de autores que forman parte de ella, en particular a escritoras de origen árabe que han nacido o se han formado en Occidente (Soto Aranda, 2019b). Entre otros, cabe mencionar nombres consagrados en los polisistemas literarios con mayor peso en la LIJ internacional, Selim Alafenisch, Ghazi Abdel-Qadir y Shafik Schami en Alemania (Berman 2011); Zeina Abirrached, Faïza Guène, Azouz Begag y Farid Boudjellal en Francia (Bonn 2000); e Ibtisam Barakat en los EE. UU.

Más recientemente podemos sumar a esta lista escritoras más jóvenes, pertenecientes a polisistemas con una menor proyección en la LIJ internacional, pero cuyas obras destacan por su impacto mediático y editorial, es el caso de la italiana Randa Ghazy y la australiana Randa Abdel-Fattah. Al respecto, a pesar de estar situada en el hemisferio sur, a Australia se le considera un país occidental, debido a que las instituciones políticas y legales, así como la lengua y literatura predominantes entre la población tienen raíces europeas, particularmente británicas.

En sus novelas, Abdel-Fattah y Ghazy suelen recurrir a protagonistas femeninas que muestran quiénes son los hijos de las familias inmigradas (Stephens y McCallum 2009), y cuál es la relación de estos con las culturas y lenguas de partida (Serageldin 2013), haciendo uso de la ironía para criticar los estereotipos anti musulmanes (Haines 2015). En la línea expuesta por diversos estudios sociológicos realizados en los últimos años (Aparicio y Portes 2014; De Pedro, Martínez y Ventura 2016), ambas escritoras sostienen que más allá de algunos referentes culturales simbólicos que pueden compartir con las culturas de partida, las migraciones crean identidades híbridas que forman parte de las sociedades de acogida, por mucho que difieran del canon ideal de ciudadanía (García 2003). A su vez, retratan a las sociedades contemporáneas en tanto que sociedades de acogida: complejas, contradictorias, híbridas y multiculturales (Vidal Claramonte 2009).

Does my head look big in this?, primera novela de Abdel-Fattah publicada a los 18 años, narra las vivencias de la segunda generación de inmigrantes en Australia, incidiendo especialmente en la población musulmana. En ella, Abdel-Fattah plasma la transformación de la personalidad de su protagonista, Amal, una joven de clase media, cuyos padres son médicos de origen palestino. Todo ello en un momento crucial de su adolescencia, su ingreso en un prestigioso colegio privado para estudiar bachillerato, situación en la que se plantea ponerse el hijab. A través de sus experiencias personales, familiares, educativas y sociales, 
Amal dibuja un mundo poliédrico y complejo que rompe con los estereotipos a los que nos tienen acostumbrados la literatura, el cine y los medios de comunicación sobre la inmigración (Lochte 2010; Zannettino 2007), a la vez que retrata una sociedad de acogida plural y en continua transformación.

Abdel-Fattah conforma un universo narrativo en el que Amal ejerce la agencia de contar su historia como autoafirmación, subvirtiendo a ojos de la sociedad de acogida la distinción entre el yo (el endogrupo) y el otro (el exogrupo), para lo que recurre a un formato literario a caballo entre el diario y la biografía novelada, dos géneros característicos de la literatura postcolonial (Vega 2003). Abdel-Fattah pone en práctica un planteamiento de corte poscolonial y feminista, según el cual, son las mujeres, las que deben ejercer su agencia como narradoras de historias que no suelen aparecer en la literatura o en la prensa, rompiendo de este modo una narrativa hegemónica sobre la otredad y las minorías (Mignolo 2005; Spivak 1998).

Aunque la editorial Pan MacMillan Australia publicó la novela en 2005, logrando el premio Australian Book Industry Award, fue su reedición por la editorial americana Scholastic en 2007 la que abrió puerta de su traducción a otros idiomas y su difusión internacional. Por último, la novela ha recibido premios como el Popular Paperbacks for Young Adults (2013) y se ha convertido en una lectura de referencia en el marco de la enseñanza de inglés como lengua extranjera, por su reflexión sobre la multiculturalidad y el uso del inglés australiano.

\section{Caracterización de la segunda generación en Does my head look big in this?}

Abdel-Fattah sitúa a Amal en un espacio definido por Bhabha (1994) como tercer espacio: un lugar de enunciación simbólico donde las diferencias culturales se construyen y se negocian. Como personaje in-between, representativo de la llamada segunda generación, Amal ejerce de traductora, una suerte de mediadora intercultural, mostrando a los lectores el significado de los nombres propios de los personajes como en el siguiente ejemplo: "Mi madre se llama Jamilia, que en árabe quiere decir hermosa” (Abdel-Fattah 2008: 7). ${ }^{1}$

Más adelante, traduce el nombre de su amiga Yasmeen: "Yasmeen es la palabra árabe para Jasmine. Cuando salimos, a Yasmeen le gusta que la llamen Jasmine, porque piensa que suena más exótico. Cuando le explico que normalmente son las palabras no inglesas las que se consideran exóticas, me dice que cierre el pico” (Abdel-Fattah 2008: 21). En 
esta cita, Amal plantea la cuestión del exotismo con relación a los nombres, y ese sentimiento ambiguo característico de la adolescencia, de querer pasar desapercibido en ocasiones, y de optar por resaltar la diferencia mediante marcas identitarias, como la vestimenta o los nombres, en otras.

A su vez, ejerce de mediadora intercultural, explicando al lector determinados elementos discursivos del árabe. En el siguiente fragmento, habla sobre los vocativos y sus valores pragmáticos:

Aunque mis padres me hablan sobre todo en inglés, hay algunas palabras árabes que instintivamente forman parte de su vocabulario cotidiano. Yallab significa "venga, vamos", o "date prisa". Cuando mis padres están especialmente cariñosos, entonces le anteponen a mi nombre un ya, de forma que soy "ya Amal”, que sería como "oh Amal”. De hecho, cuando era pequeña llegué a la conclusión de que mi nombre era Yaamal. Si he hecho algo malo, no me ponen el ya, y paso a ser simplemente "Amal". Y ya me puedo ir preparando. (Abdel-Fattah 2008: 24)

Amal no solo traduce el significado de la expresión yallab sino que explica las connotaciones que puede tener la forma en la que sus padres se dirigen a ella. Al respecto, cabe señalar que, en árabe, yā es un vocativo que se antepone al nombre de una persona cuando uno se dirige a ella, para mostrar un trato cortés y respetuoso.

En otro momento del relato, la protagonista explica tradiciones culturales como el hecho de llamar a los adultos con términos como "tía materna" si es mujer o "tío paterno" si es hombre, como signo de respeto y de buena educación, como muestra el siguiente ejemplo: "La tía Cassandra y el tío Tariq no son parientes nuestros, pero en la cultura árabe llamamos tío y tía a la mayoría de los adultos que son amigos de la familia. Sus hijos son "primos". Así que tenemos una "familia” extensa bastante amplia” (Abdel-Fattah 2008: 104).

Para visibilizar a la lengua y la cultura de origen de Amal, AbdelFattah recurre a tres procedimientos. En primer lugar, incluye una profusión de culturemas árabes en el discurso de los personajes:

a) Términos con función de vocativo culturalmente marcado, como habibti (querida) y yallab (vamos/venga);

b) Términos relacionados con la religión: fajr (nombre con el que se denomina la oración del alba; Assalamu alaikum (Saludo que literalmente significa 'que la paz sea con vosotros'); wudub (abluciones); Eid al-fitr (Fiesta del desayuno - fiesta con la que concluye el Ramadán o mes del ayuno), kola Sana Winta Bikhair (fórmula de felicitación utilizada en las fiestas religiosas), Eid Mubarak (feliz fiesta), Allab (Dios), 
inshallab (lit. `si Dios quiere'), mashallah (fórmula de agradecimiento a Dios).

c) Referencias culinarias: Makluba (plato típico de Palestina y Siria, presente también en otras cocinas orientales como la turca, elaborado con arroz, carne y verduras, principalmente berenjena y coliflor), Mansaf (plato típico jordano de origen beduino, elaborado a base de arroz, carne y yogur), fatoosh (plato típico palestino, presente también en otras cocinas orientales como la siria y la turca, elaborado a base de hortalizas con pan de pita cortado en tiras y frito o asado), warak aineb (hojas de parra rellenas de arror), koftas (bolas de carne picada especiada).

En segundo lugar, Amal y su madre hacen gala de actitudes lingüísticas propias de hablantes bilingües. En el siguiente fragmento, por ejemplo, la madre de Amal explica cómo, recién llegada a Australia, recurría a la alternancia de códigos con el propósito de expresar sus sentimientos sin molestar a su interlocutor. En ese momento, Amal señala la aparente contradicción entre el comentario de su madre y la forma en que sus padres la educan ahora:

Tu padre, Amal, me solía decir: "si alguien te hace la puñeta, ponte a insultarlos en árabe. Al menos te sacarás de la frustración”, con la salvedad de que el otro no entendería lo que decía y además utilizaba expresiones que en la lengua meta no tienen connotación como "malditos seáis tú y tu bigote". ¡Mamá! -digo_ ¿ Cómo es que papá te animaba a decir tacos, si le da un ataque cuando yo...? (Abdel-Fattah 2008: 106)

Contradicción esta que su madre se apresurará a aclarar diciendo lo siguiente: " "No creía que fuera una cosa maleducada, porque el otro no entendería lo que decía", responde severa mi madre" (Abdel-Fattah 2008: 106).

En este otro, se recurre a la alternancia de códigos para subrayar una idea, lo que pone de manifiesto la importancia de las actitudes y el componente afectivo para explicar los usos lingüísticos (Corredor 2018). Así, aunque madres e hijas hablan entre ellas en inglés, al finalizar la escena en la que rememoran sus primeras experiencias en Australia, Amal dice: "nuestras madres nos miran, sonríen y luego nos dicen, la tía Cassandra en urdu y mamá en árabe, que crezcamos ya" (Abdel-Fattah 2008: 108).

Amal, por su parte, incide en la diferencia existente entre el significado literal y el metafórico en una lengua dada y los efectos que produce la traducción literal de una expresión a otro idioma: "Pero a mí me parece graciosísimo. O sea, ¿insultar al pelo facial de la gente? Debe de haber algo que se pierde en la traducción" (Abdel-Fattah 2008: 106). 
En otra reflexión, Amal refiere un ejemplo de error pragmalingüístico habitual en las producciones de hablantes no nativos de una L2 en interacciones comunicativas espontáneas, en la que el hablante utiliza una fórmula propia de su L1, con un significado del que carece en la L2 (Alcón Soler 1996): “Otro insulto árabe que me parte de la risa es uno que usan mis padres cuando se enfadan mucho conmigo. En lugar de insultarme, ¡se insultan ellos mismos! Cuando mi padre dice "Maldito sea tu padre", es que no puedo aguantar las ganas de decirle que lo está haciendo totalmente al revés” (Abdel-Fattah 2008: 107).

\section{4. ¿De aquí o de allá? La identidad cultural de la segunda generación}

Sin embargo, a pesar de las constantes referencias al árabe, y a la cultura de partida, y su reconocimiento como componentes de la identidad de la segunda generación de inmigrantes árabes en Australia, AbdelFattah plantea la tesis de que la segunda generación es parte de la sociedad de acogida, para lo que recurre a tres estrategias: a) una interpretación semiótica del concepto de identidad; b) la autoafirmación de la protagonista en una situación de acoso escolar en el instituto; y c) la descripción de la identidad como un proceso constructivo y de negociación, en línea con los postulados poscolonialistas (Mignolo 1996; Schuttenberg 2007).

La primera estrategia se escenifica con una referencia al himno nacional australiano, que Amal cantaba a diario en el colegio islámico en el que estudió educación secundaria:

No puedo dejar de pensar en Hidaya y me pongo mala de nostalgia de mis amigos y profesores. Enferma de añoranza por una escuela donde aprendías lo mismo que los alumnos de cualquier otra escuela de Melbourne, pero también podías rezar y ayunar y llevar el hijab y seguir siendo una adolescente sin tener que responder a preguntas o defenderte de los titulares. Donde cantabas Advance Australia Fair en la congregación todas las mañanas y te quedabas castigada después de clase si no te lo tomabas en serio. Donde podías sufrir tu pubertad y esa angustia de la edad del pavo y quedarte colgada un chico y hacer tus dietas sin ser sinónimo de terrorismo, extremismo, radicalismo y otros "ismos". (Abdel-Fattah 2008: 15)

En Australia, cantar el himno es obligatorio en los colegios, a pesar de las críticas que ha generado su letra por la falta de referencias a los aborígenes y el velado elogio a la colonización británica. En este caso, la comunidad musulmana asume como propio uno de los elementos más 
simbólicos de la representación del estado, incidiendo en el acatamiento de la legalidad vigente en el país. La alusión himno nacional es una declaración en toda regla, una metáfora de la pertenencia de la segunda generación a la sociedad de acogida, que rompe la semiótica de la separación entre el endogrupo (población nativa) y los exogrupos (poblaciones migrantes), planteando una realidad social que no siempre acomoda a teorías como la del choque de civilizaciones formulada por Huntington (1996), ${ }^{2}$ precisamente cuando su concepción de lo que es una civilización pivota sobre el concepto de religión.

La segunda estrategia es la autoafirmación de Amal como australiana cuando Tía, una compañera de clase, le espeta: “[...] ¿Por qué no te vas de una vez de nuestro país y vuelves a una cueva del desierto, que es donde tendrías que estar?" A lo que ella responde: "este es mi país, y si lo vuelves a olvidar, te juro que te arranco la cabeza!" (Abdel-Fattah 2008: 233).

Abdel-Fattah desarrolla la tercera estrategia a lo largo de la obra, plasmando el proceso de maduración de la protagonista. Amal comienza la novela haciendo algo muy propio de los jóvenes: listas; listas de ideas, de pros y contras de ponerse el hijab, planteando de forma introspectiva qué supone ser musulmán/a en las sociedades contemporáneas y cómo compatibilizar sus gustos musicales, televisivos y de vestimenta, mencionados explícita y constantemente a lo largo de la novela, y compartidos con muchos jóvenes australianos, con una serie de principios religioso-morales a los que no desea renunciar. Ello descrito en slang, la jerga de registro informal y coloquial que usan otros jóvenes australianos como ella. Abdel-Fattah resuelve la cuestión de la identidad de forma muy clara al final de la novela, cuando Amal dice:

Bueno, he decidido que ya he resuelto lo de la identidad. El próximo capítulo de mi vida ni siquiera se va a mencionar la palabrita. En cambio, he decidido que escribiré otra lista. Tengo la de "llevar o no llevar". Luego he hecho la de "ir al juzgado o trabajar en un laboratorio". Ahora iré a lo más básico, directa a la fuente: Ser o no ser. Pero ¿sabes qué? Esta vez no necesito hacer la lista. Ni siquiera tengo que pensarlo. Porque algo me dice que ya sé qué lado va a ganar esta vez. (Abdel-Fattah 2008: 340)

Este es el final de la novela en el que la protagonista se propone ir más allá de la apariencia física -el hecho de llevar hijab- en busca de su verdadera condición de ser, un ser en plenitud de conciencia y de acción, que se plantea qué hacer. Pero, ¿qué significa ‘ser'? Lo que Amal se plantea es cómo interpretar su identidad, cómo tomar conciencia de ella, en consonancia con la idea sostenida por Hall (1996: 17), de que la identidad "se construye de múltiples maneras a través de discursos, prácticas 
y posiciones diferentes, a menudo cruzados y antagónicos. Están sujetas a una historización radical, y a un constante proceso de cambio y transformación”. Así, la propia Amal termina confesando:

Algunos lo encuentran irónico, pero cuando lo pienso, son especialmente los emigrantes los que me han inspirado en mi vida para comprender lo que significa ser australiana [Aussie en el original]. Ser una australiana con guiones.

Han sido los "moros”, las "cabeza pañal”, los “extranjeros", las “personas de aspecto árabe", los asiáticos, las mujeres "oprimidas", la pensionista griega ortodoxa que fuma en cadena, los "italiani macarroni", los "étnicos", los de mente cerrada y los leídos, los aspirantes a "Cocodrilo Dundee", el director de orejas peludas que me enseñó que soy un adjetivo lleno de matices. Son sus historias y sus luchas, sus dolores y sus alegrías, las que me han dado la fuerza para conocerme a mí misma, me han retado para que acepte de buena gana mi identidad de chica australiana-palestina-musulmana. (AbdelFattah 2008: 340)

En esta reflexión, la protagonista relaciona la cuestión de la identidad con el concepto de nación ¿Qué es ser australiano? Aussie es un término procedente del argot popular que se utiliza para designar a los australianos de forma genérica, pero también a los ciudadanos blancos de origen europeo. Y aquí se explicita la contradicción intrínseca en el uso de dicho término. Al fin y al cabo, ¿quién, salvo los aborígenes, no tiene orígenes foráneos en Australia? Abdel-Fattah se pronunciará en este sentido en un ensayo posterior, afirmando lo siguiente:

Si tuviéramos que abordar la cuestión de quiénes somos como nación como si de un rompecabezas se tratara, entonces la forma más lógica y coherente de hacerlo es ensamblar primero las piezas que forman el marco del rompecabezas para poder comprender lo que contiene [...]. Sabemos que el marco de Australia es la raza. Como puesto de avanzada colonial de colonos blancos del Imperio británico, solo podría ser racial. La desposesión, el genocidio y la explotación sobre los que se fundó este país; el legado de su condición de colonia británica con colonos; los esfuerzos de Australia en el pasado para construir una nación racialmente excluyente a través de la política de Australia Blanca; su evolución de dominio "racial" a "cultural" a través del vehículo de una política de multiculturalismo altamente politizada; y, sobre todo, la negación de la soberanía indígena - los pueblos racializados saben que es aquí donde debe comenzar cualquier discusión sobre la identidad de esta nación. (Abdel-Fattah, 2018)

Amal se considera a sí misma una australiana con guiones, porque su identidad no resultaría completa sin sus otros componentes: ser palestina y ser musulmana, como bagaje incorporado a su esencia. Cabe señalar cómo al final de novela, la protagonista asume los guiones como 
parte de su realidad, frente al comentario que aparece al inicio de la obra. Como dice la protagonista "Soy australiana-musulmana-palestina. Eso quiere decir que nací australiana y con el cachete en el culo me dieron también unos cuantos guiones de identidad que me dejaron bien confundida" (Abdel-Fattah 2008: 9).

En este aspecto de su identidad coinciden Amal y la propia autora, presentada en la contraportada de la novela como una representante de la cultura árabe, auto confesa "nacida-australiana-musulmana-palestinaegipcia-enamorada del chocolate”. Así, tanto en la contraportada en inglés como en la de la traducción al español, la describen como "representante de la segunda generación de inmigrantes árabes; mujer; formada [es abogada]; miembro del Consejo Árabe de Australia; activista de los derechos humanos y libre”.

\section{La inmigración y la sociedad de acogida: dos realidades plurales}

La novela presenta los procesos de transformación y adaptación social protagonizados por la primera generación de inmigrantes musulmanes en Australia desde dos perspectivas complementarias. Por un lado, encontramos a tres mujeres de la primera generación: Jamila (la madre de Amal, palestina) y las madres de Laila y Yasmeen, dos amigas de la protagonista; la primera es turca y la segunda es inglesa, conversa al islam y casada con un paquistaní. Las tres narran en primera persona cómo vivieron ellas el proceso de integración en la sociedad australiana. Jamila estudió medicina. Al inicio de su nueva vida en Australia tuvo problemas con el inglés y como jóvenes que eran, ella y su esposo deseaban romper esquemas.

Pero ¡no sabes los problemas que tuve con el inglés! Nos sentíamos como discapacitados. Me acuerdo que fui al supermercado y pedí un kilo de carne "pinchada”. El chico no me entendía y llamó a alguien que lo ayudara. Yo seguía insistiendo en la carne "pinchada". Cuando al fin se dieron cuenta de que quería carne picada, no paraban de reírse. Qué vergüenza pasé. Todas nos reímos.

_ Sí, ahora hace mucha gracia. Pero entonces éramos jóvenes y recién llegados, y la gente nos miraba como si fuéramos marcianos. Algunos no tenían paciencia con nuestro problema con el lenguaje. [...]_Ay, también tuvimos nuestros buenos momentos. Nos besábamos en público y la gente se molestaba. (Abdel-Fattah 2008: 105) 
Pero no solo las personas procedentes de lugares en los que se habla una lengua distinta a la lengua vehicular de la sociedad de acogida deben superar dificultades en su proceso de integración y adaptación social. En el caso de Cassandra, la madre de Yasmeen, la diferencia lingüística se traduce en el acento: “_A mí me pasó que la gente no entendía mi acento inglés _dice la tía Casandra” (Abdel-Fattah 2008: 105); a ello hay que unir el hecho de ser de origen británico y estar casada con un paquistaní: “_En fin, me acuerdo de que la gente era muy maleducada y me llamaba británica de mierda y me decían que hablaba raro. Y tuve que soportar bastantes caras de pocos amigos porque también llevaba el velo "bueno, el gorrito de ganchillo" y estaba casada con un paquistaní" (Abdel-Fattah 2008: 105).

No obstante, el mensaje es muy claro, si la primera generación se pudo adaptar, ellos tienen que sobreponerse a las dificultades: “ $¿$ Veis, chicas?, dice tía Cassandra, nosotras también fuimos jóvenes y nos costó lo nuestro adaptarnos a un país nuevo. Si nosotras podemos hacerlo, vosotras no tendréis ningún problema, habiendo nacido aquí. Podréis enfrentaros a cualquier obstáculo que se os presente" (Abdel-Fattah 2008: 107).

Por oposición al discurso de Jamilia y de Casandra, emerge la figura de la madre de Leila, personaje que se adecúa al prototipo de la mujer musulmana que aparece en los medios de comunicación (El-Madkouri 2004a y Piquer Martí 2015). Procedente de Turquía, casada joven, sin estudio, para quien las tradiciones están por encima de los principios religiosos. su aspiración vitral es que su hija se case. Hablando sobre el matrimonio, Leila afirma:

¡No! Nunca llegaría a obligarme. Sólo que me presiona constantemente con que me dedico demasiado a los estudios y no a pensar en sentar la cabeza. Es extraño, porque mis primas de Turquía están todas en la universidad y sus padres, que son mis tíos y tías, tendrían un ataque si las chicas quisieran casarse antes de terminar la carrera. La cosa es que mamá vino hace un montón de años con las tradiciones de su pueble y se quedó atrapada en un buque del tiempo, mientras sus hermanos progresaban. (Abdel-Fattah 2008: 144)

Así, la autora compara la figura de la madre de Laila con la madre de Eleen, de distinto bagaje religioso, pero con la que comparte esa forma particular de entender el mundo: "Sé exactamente lo que quieres decir" dice Eleen. Mis padres emigraron de Japón hace veinte años y aún están hablando de las tradiciones y normas culturales que seguían cuando se fueron, hace mogollón de años" (Abdel-Fattah 2008: 144).

Abdel-Fattah describe al detalle el hecho de que, en ocasiones, los inmigrantes se refugian en las tradiciones como un recurso para enfrentarse a la inseguridad y el miedo que produce tener que afrontar su inte- 
gración en la sociedad meta. Ese asirse a las tradiciones provoca que los inmigrantes se queden aislados, no solo de la sociedad de acogida sino de la propia sociedad de partida. Pues como ha expuesto El-Madkouri (2006: 99), “más allá de las imágenes estereotipadas sobre las sociedades de las que proceden los flujos migratorios en Occidente, estas están en continuo proceso de cambio y de transformación”. Abdel-Fattah ejemplifica esta situación al detalle, como puede comprobarse en los siguientes fragmentos, el primero referido a la madre de Eleen, y el segundo, a la madre de Leila:

Lo extraño fue que cuando fuimos de vacaciones a Japón hace un par de años, mis tías, que son mayores que mi madre, llevaban quimonos mucho más modernos que el suyo. Estaban realmente a la última en moda y estilo, y mi madre, allí, con su gusto de hace veinte años. (Abdel-Fattah 2008: 144)

_Me siento muy identificada con eso_dice Leila_. Mi madre insiste en ponerse unos pañuelos de flores con remates de encaje. Mis primas le estuvieron dando la vara con eso cuando estuvimos en Turquía. Ellas llevan unos tejidos de seda y raso maravillosos, con unos estampados muy modernos, y mi madre va con esa cosa que podría pasar por un tapete. (Abdel-Fattah 2008: 145)

La inmigración es una realidad plural, incluyendo la población musulmana. Por ello, si las mujeres representan diferentes formas de integración, Abdel-Fattah presenta al tío materno de Amal, Joe, como un ejemplo de asimilación cultural: "con una sala de estar llena de koalas y banderas australianas que le resulta como "un santuario para los desesperados por ser genuinamente australianos y conseguir la salvación a través de la identidad" (Abdel-Fattah 2008: 175). De este modo, Joe representaría el polo extremo de un proceso de aculturación, en el que "los inmigrantes renuncian a la identificación con la cultura de origen y, de forma gradual, se deben identificar al máximo con las características culturales de la sociedad de acogida, adoptando las normas, los valores, las actitudes y los comportamientos como los de la sociedad de acogida” (Ramírez López 2017: 55).

En la novela, Joe, su mujer y sus hijos han adoptado nombres ingleses y presumen de relacionarse solo con la comunidad “anglo". Son personas con unos valores contradictorios, particularmente por lo que se refiere a sus actitudes hacia su hija Samantha y el novio de esta, Martin, como muestra esta cita: "Aunque sus padres pueden ser muy relajados con la religión y la cultura nunca aceptarían que Samantha tuviera novio. O sea, que cuando sale con Martin, ellos se tragan cualquier historia sobre que va a estudiar a casa de alguien" (Abdel-Fattah 2008: 97). Más aún, los padres de Samantha saben que ella bebe y que fuma, pero no aceptan que su hija tenga relaciones con un chico: 
Saben que bebo. Eso no les preocupa. El problema es que estuviera con Martin. Ahora creen que me acuesto con él [...] Luego, imagínate: ¡papá va y me saca lo de la teoría cultural! Me empieza a dar la va con lo de que no es parte de nuestra cultura. Ahí no pude aguantarme. O sea, no puede usar la excusa de la cultura sólo cuando le conviene. Llevamos dos décadas oyendo lo de que "tenemos que integrarnos" y ahora, de repente, en un minuto ya tenemos raices árabes $y$ expectativas culturales. ${ }^{3}$

"Te lo puedes creer? Y eso lo dice el hombre que piensa que la palabra 'extranjero' es la palabrota de nuestra era. Toda la vida nos han hecho tragar a George y a mí que tenemos que olvidar nuestra cultura y vivir como australiano, como si eso significara algo. Pero cuando hago algo que no le gusta, da un giro de ciento ochenta grados". (Abdel-Fattah 2008: 102)

Y del mismo modo que las comunidades de inmigrantes son loci de pluralidad, diversidad y contradicción, Abdel-Fattah plantea que la sociedad de acogida tampoco constituye un locus de pensamiento homogéneo. Así, algunos personajes también se interesan sobre sus costumbres y modo de vida de los musulmanes, y son Amal y Eleen las que desvelan la complejidad de apelativos como religioso en sociedades occidentales secularizadas. Simone se atreve a preguntar a Leila si la forma de vestirse y de actuar de su madre corresponde al de una persona religiosa: “_ ¿Es porque es religiosa? _Le pregunta Simone a Leila_. Amal siempre nos taladra con que las tradiciones de tipo talibán no son islámicas, pero a veces es un lío” (Abdel-Fattah 2008: 145). Abdel-Fattah aprovecha la respuesta de Laila para mostrar diferentes aproximaciones al hecho religioso dentro de la comunidad musulmana:

"Depende de lo que consideres religioso", responde Leila. Mi madre sigue más sus propias costumbres que el islam. No tiene un verdadero conocimiento de la religión, ¿ ‘sabes? En cambio, mis parientes de Turquía están muy informados y educados en el islam. Las chicas rezan, y algunas llevan el velo y van a la universidad y trabajan, porque saben que tienen derecho a hacerlo según el islam. Mi madre es más adepta a seguir costumbres sociales. (Abdel-Fattah 2008: 145)

No obstante, la autora también pone de manifiesto ciertos comportamientos sociales como el racismo, que en el caso de Australia se focaliza de forma más intensa en la población aborigen. Así, el jefe de estudios, el Sr. Pearce, afirma lo siguiente:

No soy tonto, Amal. Sé que la gente te juzga. Te diré algo personal. Mi pareja es aborigen. Cuando vamos juntos por la calle, notamos que la gente nos mira, murmura y levanta las cejas. Ella siempre tiene que enfrentarse a las suposiciones. Las generalizaciones. Todos los aborígenes son alcohólicos, cobran el paro y no buscan trabajo. Esas cosas que salen en los medios y que los políticos fabrican para ganar puntos. (Abdel-Fattah, 2008: 288) 
En suma, no hay mundos estancos. Más allá de las imágenes estereotipadas, la diversidad interna existe tanto entre la inmigración como en las sociedades de origen y de acogida (El-Madkouri 2004b).

\section{Representación de la segunda generación y de la cultura de partida en la traducción al árabe de Does my head look big in this?}

La editorial británico-catarí Bloomsbury Qatar Fundation Publishing (BQFP) publicó la traducción al árabe de Does my head look big in this? en 2012, con el título Mā rāyukum fī ŝaklī al-ān [trad. it. ¿¿Qué opinas de mi apariencia ahora?]. Esta reproduce las referencias culturales mencionadas en la novela de Abdel-Fattah, es el caso de series de televisión como Friends y ¿Quién quiere ser millonario?, películas como El señor de los anillos y personajes televisivos como Oprah Winfrey, entre otras. También conserva referencias interculturales como el pasaje en el que la protagonista narra su experiencia en una escuela religiosa católica. Así, la escena en la que se le ocurre entrar en un confesionario y confesarse está traducida íntegramente al árabe. En este contexto, se han traducido términos "eucarístico", “comunión” y "hostia consagrada” por sus equivalentes en árabe. En el caso de "cinco avemarías y cinco padrenuestros", la contestación del padre Andrews cuando ella dice que es musulmana, en la traducción se ha utilizado una expresión de uso más común entre los cristianos árabes, "en el nombre de la Cruz, de Cristo y de María”.

Sin embargo, los siguientes fragmentos textuales han sido suprimidos en la traducción:

a) Referencia ofensiva en la cultura meta. La autora plantea situaciones de discriminación o de ofensa de forma muy directa, recurriendo a la exageración y al sarcasmo para subrayarlas. Así, por ejemplo, la protagonista relata un caso de acoso escolar en el que los compañeros de Amal se reían de su nombre:

Eh, Amal, ¿por qué un estornudo suena como una letra del alfabeto árabe?

Eh, Amal, ¿quieres patatas de queso con beicon?

Eh, Amal, ¿tienes un camello en tu casa?

El, Amal, ¿Te has dado cuenta de que el profe sustituto te ha llamado "Anal" al pasar lista? (Abdel-Fattah 2008: 13)

En los comentarios hay alusiones al beicon (el cerdo es una comida prohibida para los musulmanes), que la traductora vierte al 
árabe literalmente, así como la referencia al camello como un elemento identificativo de la cultura árabe en Occidente. Sin embargo, la última pregunta ha sido suprimida en la traducción. Existe un término equivalente a término anal en árabe, pero la connotación de ofensa que adquiere en el texto resulta inconcebible en la cultura meta y menos en una obra para lectores jóvenes.

b) Explicaciones del significado de palabras árabes. La supresión de fragmentos en los que se explica el significado de términos árabes invisibiliza una de las características de la segunda generación de inmigrantes en países occidentales, su papel de mediadores culturales. En los siguientes ejemplos se ha suprimido la expresión en cursiva: "Mi madre se llama Jamila, que en árabe quiere decir hermosa" (Abdel-Fattah 2008: 7); "Cuando mis padres están especialmente cariñosos, entonces le anteponen a mi nombre un ya, de forma que soy "ya Amal", que sería como "ob Amal" (Abdel-Fattah 2008: 22) y "Mi padre me despierta para rezar el fajr, la primera oración de la mañana" (Abdel-Fattah 2008: 26). Por su parte, la siguiente frase se ha suprimido completamente: "Yallah significa "venga, vamos”, o "date prisa”" (Abdel-Fattah 2008: 23);

c) Referencia a modelos de familias que se alejan de las normas sociales imperantes en la cultura árabe. En la siguiente cita, la protagonista explica cómo se conocieron los padres de su amiga Yasmeen, aunque el fragmento en cursiva, en el que se describe a su padre bebiendo alcohol, ha sido suprimido de la traducción.

El padre de Yasmeen es paquistaní, y su madre es británica. La madre se convirtió al islam cuando estudiaba historia y sociología en la universidad, en Londres. Alí conoció al padre de Yasmeen, que pasaba la mayor parte del tiempo libre en el pub, o sea que no era precisamente el más ferviente embajador del islam. Cassandra estaba haciendo entonces su tesis sobre los musulmanes británicos. Una noche, en un bar del campus, oyó casualmente que un tal Abdel-Tariq levantaba una cerveza y hacia un sonoro brindis por "Cat Stevens, ${ }^{4}$ la Reina Madre y el formidable Mini". Habia encontrado el primer capitulo de su tesis y a su futuro marido. (Abdel-Fattah 2008: 21)

Igualmente, la referencia a la procedencia de los padres de Rahul, el primer novio de su prima Samantha, señalada en cursiva, ha sido suprimida: “ “'Te acuerdas de Rahul? ¿El tío al que dejé en primer curso, porque me hacía pagarlo todo y me pidió dinero prestado para comprarme un regalo de cumpleaños? Que su padre es indio y su madre egipcia"” (Abdel-Fattah 2008: 101). Desde el punto de vista de la tradición, particularmente en 
los países del Golfo, no se concibe que una mujer se case con un extranjero, y menos si este es de una confesión religiosa diferente, información que no se menciona en el texto.

d) Referencias al hijab. Se ha suprimido la frase: "las "media jornada" como yo llevamos el hijab como parte del uniforme en una escuela islámica o cuando vamos a la mezquita, e incluso en uno de esos días que no sabes qué hacer con el pelo" (Abdel-Fattah 2008: 6). Se trata de un comentario irónico que desdramatiza del uso del hijab, además de una crítica al uso social que esta prenda tiene en las sociedades árabes.

c) Situaciones en las que se cuestiona la autoridad de los padres o lo que estos hacen. Así, se ha suprimido el fragmento en el que la protagonista dice:

En cuanto a mi padre, sólo tengo que insinuar que tengo "dolor de barriga" o "cosas de mujeres" para salirme con la mía. Papá dice que no debería ver Sexo en Nueva York, porque me va a pudrir el cerebro. Yo respondo con un tonito mustio de "qué pena de mí" que tengo unos dolores terribles y que, si le importaría traerme el paracetamol, que no me puedo mover del sofá. Entonces se olvida el programa y se va a hablar con mi madre. A mí me da tiempo de ver si Samantha se liga al cartero. Es sólo cuestión de montarte un sistema para manipular a los padres. (Abdel-Fattah 2008: 8)

Igualmente, se ha censurado otra intervención en la que su madre le dice a Amal: “¿De verdad? La única persona que me parece que tiene un grave caso de síndrome premenstrual eres tú”. (Abdel-Fattah 2008: 67). Y una escena en la que se representa una discusión entre Amal y sus padres, a cuenta de su decisión de ponerse el hijab: "Él intenta hacerse el herido, y ella le echa una mirada demasiado seductora para mi gusto. Él le guiña el ojo y se ríen como si fuera la primera vez que salen juntos o algo. Ver a mis padres ponerse así de tortolitos es como para vomitar" (Abdel-Fattah 2008: 26).

f) Partes del cuerpo. La censura se aplica en dos momentos de la novela en la que Amal hace referencia a las nalgas. El primero, cuando la directora del nuevo instituto le pregunta si la idea de ponerse el hijab es suya: "Cambio de posición en la silla. Tengo el culo dormido de lo dura que está. “ ¿Decisión tuya taparte toda? [le pregunta la directora]". Noto en ella un leve deje de escepticismo. La mira perpleja: "sí, ha sido decisión mía"” (Abdel-Fattah 2008: 39). El segundo, cuando Amal le explica al jefe de estudios del instituto la razón por la que no desea 
rezar en la clase. El fragmento censurado constituye además una crítica de las imágenes que los medios de comunicación suelen publicar sobre los musulmanes:

¿Te vale una clase vacía? Te lo puedo arreglar si te parece bien._Bueno, ¿ha visto usted reportajes donde la cámara hace un zoom en un grupo de musulmanes rezando? ¿La escena "culos arriba"? Nadie se fija en los otros movimientos de los que rezan, las cámaras siempre van a los culos. O sea, que no me gustaría estar en una clase con el culo en pompa y que la gente pase y piense que me va el yoga individual... Echa una carcajada [el jefe de estudios]. (Abdel-Fattah 2008: 47)

Con el fin de analizar los segmentos textuales censurados de forma objetiva, entrevistamos a la traductora, la omaní Zuwaina Altuwayya, planteándole cuestiones relacionadas con la representación de las culturas a través de la traducción, así como otras relativas a las indicaciones que había recibido de la editorial para realizar la traducción. Por un lado, le preguntamos si con la traducción había tratado de acercar el libro a los lectores árabes o si, por el contrario, su objetivo había sido el de conseguir que estos fueran conscientes de que el libro pertenece a otra cultura, esto es, aproximar a los lectores árabes la cultura australiana, Alttawiyya manifestó lo siguiente:

La novela se sitúa en Melburne y la narradora es un adolescente arabo-australiana que ha nacido y crecido en Australia. Ella afronta diversos cambios cuando decide llevar pañuelo (hijab) en una comunidad occidental. El lector árabe se introduce en la cultura australiana a través de la propia Amal. Yo, como traductora, he tratado de comunicar la novela a los lectores árabes a través de los ojos de Amal.

Así pues, en opinión de Altuwayya, la novela resulta potencialmente interesante para el lector árabe al presentar protagonistas árabes con los que sentirse identificado: la protagonista es una chica que estudia y tiene contradicciones propias de la adolescencia.

Alttawiyya continúa explicándose en los siguientes términos:

La escritora, de hecho, quiere decir que Amal es una adolescente normal que experimenta todo tipo de cambios que cualquier adolescente en el mundo, con independencia del hecho de que es una árabe y una musulmana que quiere llevar hijab. La atmósfera de la cultura australiana gira en torno al mundo de los adolescentes. Así que un lector adolescente árabe podría encontrarlo familiar en términos de experiencias de vida que la mayoría de los adolescentes suelen afrontar en sus vidas, da igual de dónde sean. Lo que también resulta familiar es que se trata de una comunidad multicultural con costumbres y tradiciones diversas que podrían servirle al lector para abrirse 
a nuevas experiencias compartidas por diferentes nacionalidades. Además, hay varios elementos árabes que ayudan a acercar la novela a los lectores árabes como algunos platos árabes, tradiciones, celebraciones, así como términos árabes.

Desde su punto de vista, la novela contiene referencias culturales compartidas, lo que puede facilitar el acercamiento del lector árabe a la realidad de la sociedad australiana narrada en la novela. De este modo, es de esperar que la lectura de la obra permita al lector abrirse a nuevas costumbres y tradiciones y aprender a interactuar con ellas. Esta postura coincide con una aproximación traductológica a la cultura de partida denomina ética (Carbonell 1998) o exotizante (Venuti 1995), que se esfuerza por conservar las diferencias existentes entre ambos marcos culturales. Sin embargo, la traductora afirma haber traducido el texto íntegramente: "durante el proceso de traducción, yo traduje el texto completo, pero BQFP decidió suprimir algunos de los pasajes culturalmente sensibles", y continua explicando que "el texto fue traducido, pero por alguna razón BQFP decidió suprimirlos. El texto árabe fue editado después de la traducción por un editor árabe”. De este modo, según su testimonio, fue la editorial la que decidió censurar de la traducción determinados fragmentos.

Según su testimonio, la editorial habría optado por silenciar fragmentos textuales que representan actitudes ajenas a lo que considera cánones culturalmente sancionados en el marco cultural meta, susceptibles de causar rechazo a la novela en la cultura arabo-islámica. Al respecto, cabe utilizar el concepto de "cultura arabo-islámica" en un sentido amplio pues las editoriales árabes no publican para un país concreto, sino que, con fines comerciales, consideran el conjunto de países arabófonos su marco potencial de actuación (Lambert 2000 y Soto Aranda 2014). Este sería el caso de referencias a familias mixtas formadas por una mujer musulmana y un hombre no musulmán, referencias al alcohol, o el cuestionamiento de la autoridad de los padres. Como se ha comentado, BQPS habría actuado siguiendo los patrones habituales en la LIJ, primando lo políticamente correcto en cada sociedad. Sin embargo, ello conlleva que en la traducción resulte neutralizada tanto la imagen de una población inmigrante plural y diversa que presenta AbdelFattah, como ciertos rasgos que singularizan el papel de la segunda generación como mediadora intercultural.

Asimismo, la prevalencia de las normas culturales conlleva la supresión de referencias explícitas a temas tabú en la cultura árabe que, en el caso de determinadas partes del cuerpo, supone la neutralización de la crítica social que expone Abdel-Fattah en su novela, como los insultos que recibe Amalen el colegio o la forma en que se suele fotografiar a los musulmanes cuando rezan. 


\section{Conclusiones}

La incorporación de la inmigración en las sociedades occidentales presenta un reto a la noción de la relación entre espacio y cultura derivada del concepto de estado-nación, pues no solo hace visible a las minorías, sino que pone de manifiesto la fragilidad del concepto de nación homogénea, racial y lingüísticamente (Bhabha 1994). Frente a conceptos como el choque de culturas propuesto por Huntington (1996), Randa Abdel-Fattah presenta conceptos como identidad e integración como procesos complejos, resultado de una simbiosis entre los principios, valores y cultura de las sociedades de acogida, y aquellos elementos patrimoniales de las familias inmigradas (lingüísticos, religiosos o culturales) que interaccionan con los primeros.

A su vez, la comparación del original de ¿̇or qué todos me miran la cabeza? con su traducción al árabe muestra la distancia entre el concepto de cultura árabe que presenta la autora, y la autoimagen que la editorial BQFP proyecta de la misma. Así, y si bien es verdad que en la traducción de la LIJ es habitual el uso de la censura con el objeto de domesticar un texto y aproximarlo a la cultura de destino, en el caso estudiado, su uso conlleva la eliminación de características definitorias de la novela como la crítica social, hecho que contradice la opinión de investigadores como como Kamel Anati (2010) que la incluyen dentro de la LIJ árabe, argumentando la ascendencia árabe de la autora y la profusión de referencias al árabe y la cultura árabe que contiene.

Esta novela permite entender cómo la segunda generación forma parte de las culturas meta y no de las de origen, sin olvidar que es posible preguntarse, al igual que lo hace Bourdieu (1999: 23) (citado en García 2003: 28): “¿cómo se puede considerar “inmigrantes” a personas que no han "emigrado" de ninguna parte y de las que se dice, además, que son de "segunda generación"?" Y con ellas las literaturas de sus autores. Estas literaturas son, en suma, respuesta de las sociedades multiculturales que buscan ser interculturales; reflejo de la existencia de los espacios intermedios en ellas, donde la literatura cuestiona definiciones restrictivas de identidad y pertenencia.

Beatriz Soto Aranda

Departamento de Economía Financiera y Contabilidad e Idioma Moderno

Facultad de Facultad de CC. Jurídicas y Sociales

Universidad Rey Juan Carlos

beatriz.soto@urjc.es

ORCID: 0000-0002-7389-0388

Recepción: 22/09/2020; Aceptación: 18/05/2021

Lengua y migración / Language and Migration 13:2 (2021), 125-146 Edición impresa: ISSN 1889-5425. Edición en línea: ISSN 2660-7166. (C) Universidad de Alcalá 


\section{Notas}

1 Para las citas se ha utilizado la traducción española de la novela: Abdel-Fattah, R. 2008. ¿Por qué todos me miran la cabeza? Barcelona: La Galera. Trad. de Pepa Devesa.

2 Huntington proponía que, tras el desplome del sistema bipolar, las ideologías dejan paso a las civilizaciones como actores políticos clave en las relaciones internacionales; ello incentivado por los procesos de globalización económica y técnica. Para Huntington, la religión es el componente definitorio básico de una civilización.

3 Subrayado en el original.

4 Se trata de un famoso cantautor inglés que al hacerse musulmán adoptó el nombre de Yusuf Islam.

\section{Referencias bibliográficas}

Abdel-Fattah, Randa. 2018. "Pumpkin seeds, angry minoritics and race. The moral contortions of multiculturalism". Griffith Review, 61. 84-91.

Alcón Soler, Eva. 1996. "La interacción en el proceso de adquisición de la L2". Lenguaje $y$ textos, 8. 229-238.

Aparicio, Rosa y Alejandro Portes. 2014. Crecer en España. La integración de los hijos de inmigrantes. Barcelona: Obra Social "la Caixa".

Berman, Nina. 2011. German literature on the Middle East. Discourses and Practices: 1000-1989. Michigan: The University of Michigan Press.

Bhabha, Homi. 1994. The location of culture. Londres: Routledge. Trad. al español a cargo de César Aira. El lugar de la Cultura. Buenos Aires: Manantial, 2007.

Bonn, Charles. 2000. "La littérature de jeunesse maghrébine ou immigrée: quelques paramètres d'une émergence". Études littéraires maghrébines, 20. 36-45.

Bourdieu, Pierre. 1999. Contrafuegos: reflexiones para servir a la resistencia contra la invasión neoliberal, Barcelona: Anagrama.

Carbonell, Ovidi. 1998. Traducción y cultura: de la ideología al texto. Salamanca: Ediciones Colegio de España.

Corredor, Joselyn. 2018. "Aproximación a la sociología del lenguaje: hacia unas consideraciones generales”. Cuadernos de Lingüística Hispánica, 31. 59-77.

Cronin, Michael. 2000. "History, Translation, Postcolonialism", En Changing the Terms. Translation in the Postcolonial Era, Simon Sherry y Paul St.-Pierre (eds.), 33-53. Ottawa: University of Ottawa Press.

De Pedro Herrera, Ma Dolores, Jordi Martínez Callaghan y Tirso Ventura de Pedro. 2016. Somos de aqui y de allá Las dinámicas de integración social y educativa de los jóvenes inmigrantes y sus familias. Zaragoza: Consejo Económico y Social de Aragón.

El-Madkouri, Mohamed. 2004a. "Mujer árabe y prensa española: representaciones de un colectivo migrante", Asparkia: Investigació feminista, 15. 173-192

El-Madkouri, Mohamed. 2004b. "España y el Mundo Árabe: Imagen e imaginario". Tonos digital revista española de estudios filológicos 7, junio, 1-22.

El-Madkouri, Mohamed. 2006. "El Otro. El musulmán en la prensa". En Medios de comunicación e inmigración, Mario Larío Bastida (coord.), 98-124. Murcia: Caja de Ahorros del Mediterráneo.

García, Iñaki. 2003. "Los hijos de inmigrantes extranjeros como objeto de estudio de la sociología". Revista Andaluza de Ciencias Sociales, 3. 27-45.

Gómez Pato, Rosa Marta. 2011. "Historia de la traducción de la literatura infantil y juvenil en España: nuevas aproximaciones críticas". Anuario de literatura infantil y juvenil (ALIJ), 8. 45-68. 
Haines, Colin. 2015. “Challenging Stereotypes: Randa Abdel-Fattah's Use of Parody in Does My Head Look Big in This?" Bookbird: A Journal of International Children's Literature, Johns Hopkins University , Press, 53 2. 30-35 DOI: 10.1353/bkb.2015.0032

Hall, Stuart. 1996. "Introducción: ¿Quién necesita identidad?”. En Cuestiones de identidad cultural, Stuart Hall y Paul Du Gay (coords.), 13-40. Buenos Aires-Madrid: Amorrotu.

Hermans, Theo. 1999. Translation in Systems. Descriptive and Systemoriented Approaches Explained. Manchester: St Jerome.

Hermans, Theo. 2007. "Translation, irritation and resonance". En Constructing a Sociology of Translation Michaela Wolf y Andrea Fukari (eds.), 59-78. Amsterdam: John Benjamins.

Huntington, Samuel. 1996. The Clash of Civilizations and the Remaking of World Order. Nueva York: Simon \& Schuster.

Kamel Anati, Nesreen. 2010. "Teaching through the Conflict: Examining the Value of Culturally Authentic Arabic Young Adult Literature". En Young Adult literature and adolescent identity across cultures and classrooms: Contexts for the Literary Lives of Teens, Janet Alsup (ed.), 63-80. London: Routledge.

Lambert, José. 2000, “The cultural component reconsidered". En Translation Studies: An Interdiscipline, Mary Snell-Hornby, Franz Pöchhacker y Klaus Kaindl (eds.), 17-26. Amsterdam: John Benjamins.

Lochte, Hilary. 2010. Abdel-Fattah, R. (2007). Does My Head Look Big in This? New York: Scholastic. 360 pp., International Journal of Multicultural Education, 12: 1.

Mignolo, Walter, 1996. "Los Estudios Subalternos ¿'son posmodernos o poscoloniales?: la política y las sensibilidades de las ubicaciones geo culturales". Revista de la Casa de las Américas, 204. 20-40.

Mignolo, Walter. 2005. "La razón poscolonial. Herencias coloniales, teorías poscoloniales". AdVersuS: Revista de Semiótica, 4, sin paginar. Disponible en http://www.adversus.org/indice/nro4/articulos/articulo_mingolo.htm. http://www.adversus.org/indice/nro4/articulos/articulo_mingolo.htm. Fecha de acceso: 7 septiembre 2020.

Pascua Febles, Isabel. 1998. La adaptación en la traducción de la literatura infantil. Las Palmas: Fundación MAPFRE / U. de las Palmas de Gran Canaria. Servicio de Publicaciones.

Piquer Martí, Sara. 2015. "La islamofobia en la prensa escrita española: aproximación al discurso periodístico de El País y La Razón”. Dirāsāt Hispānicas. Revista Tunecina de Estudios Hispánicos, [S.1.], 2, 137-156, jun.

Ramírez López, Ma Paz. 2017. El proceso de adaptación sociocultural: un modelo sociocognitivo de aculturación. Tesis Doctoral. Universidad de Comillas.

Schuttenberg, Mauricio. 2007. "Identidad y globalización. Elementos para repensar el concepto y su utilización en las ciencias sociales". Cuadernos de Ideas, 1/1. 1-27

Serageldin, Samia. 2013. "Perils and Pitfalls of Marketing the Arab Novel in English". En Edinburgh Companion to the Arab Novel in English: The Politics of Anglo Arab and American Arab Literature and Culture, Nouri Ghana (ed.), 426-446. Edinburgh: Edinburgh University Press.

Shavit, Zohar. 2006. "Translation of children's literature". En The translation of children's literature: a reader, Lathey, Gillian. (ed.) 25-40. Clevedon: Multilingual Matters Ltd.

Soto Aranda, Beatriz. 2014. "La literatura infantil árabe actual: mecenazgo y canon literario" Anuario De Investigación En Literatura Infantil Y Juvenil (ANILIJ), 12. 141-152.

Soto Aranda, Beatriz. 2019a. "Arabic and Islamic immigration in Children and young adult literature in Spain. Cultural Discourses in Spanish Literature and Translations". En Revisiting Centres and Peripheries in Iberian Studies: Historical Processes, Social Change and Cultural Representations. Mark Grant (ed.), 354-378. Newcastle upon Tyne: Cambridge Scholars Publishing. 
Soto Aranda, Beatriz. 2019b. "Traducir literatura infantil y juvenil de temática árabe e islámica al castellano: editoriales, normas preliminares y polisistemas literarios en contacto”. CLINA 5:1. 113-130.

Spivak, Gayatri 1988. "Can the Subaltern Speak?”. En Marxism and the Interpretation of Culture, Cary Nelson y Larry Grossberg (eds.), 271-313. Londres: Macmillan.

Stephens, John. 1990. “Advocating Multiculturalism: Migrants in Australian Children's Literature after 1972”. Children's Literature Association Quarterly, 15: 4. 180-185.

Stephens, John. y Robyn McCallum, 2009. "Positioning Otherness: (Post)Multiculturalism and Point of View in Australian Young Adult Fiction". En Belonging and Exclusion: Case Studies in Recent Australian and German Literature, Film and Theatre, Ulrike Garde y Anne Rose Meyer (eds.), 129-142. Newcastle upon Tyne: Cambridge Scholars Publishing.

Toury, Gideon. 1995. Descriptive Translation Studies and Beyond. Amsterdam and Philadelphia: John Benjamins.

Tymoczko, Maria. 2006. “Traducción, ética e ideología en la época de la globalización”, Transfer, 1 (mayo). 4-34.

Vega, $\mathrm{M}^{\mathrm{a}}$ José. 2003. Imperios de papel. Introducción a la crítica postcolonial. Crítica: Barcelona.

Venuti, Lawrence. 1995. The translator's invisibility: A History of Translation. London: Routledge.

Vidal Claramonte, África. 2009. “A (Self-)Critical Perspective of Translation Theories”. MonTi Monografías de Traducción e Interpretación, 1. 49-58.

Zannettino, Lana. 2007. "From "Looking for Alibrandi" to "Does my Head Look Big in This?": The role of Australian teenage novels in reconceptualising racialised-gendered identities". Transforming Cultures eJournal, 2:1. 96-115. 